\title{
UTILIZAÇÃO DA PLATAFORMA MOODLE EM PORTUGAL Moodle nas escolas do ensino básico e secundário em Portugal
}

\author{
Paulo Coelho Dias \\ Escola Superior de Educação do Instituto Politécnico de Santarém, Instituto Universitário \\ de Lisboa (ISCTE-IUL), Centro de Investigação e Estudos de Sociologia (CIES), Lisboa, Portugal \\ Nuno de Almeida Alves \\ Instituto Universitário de Lisboa (ISCTE-IUL), Centro de Investigação e Estudos de Sociologia \\ (CIES), Lisboa, Portugal
}

Pedro Abrantes

Instituto Universitário de Lisboa (ISCTE-IUL), Centro de Investigação e Estudos de Sociologia (CIES), Lisboa, Portugal

\section{Carla F. Rodrigues}

Instituto Universitário de Lisboa (ISCTE-IUL), Centro de Investigação e Estudos de Sociologia (CIES), Lisboa, Portugal

\begin{abstract}
Resumo Analisamos neste artigo a utilização, em Portugal, da plataforma Moodle. Por confronto com a literatura, perspetivamos o uso que lhe tem sido dado no âmbito das escolas selecionadas. Este estudo integra informação de um projeto de investigação com 2674 alunos e 324 docentes. Tanto os alunos como os professores foram inquiridos em profundidade quanto ao uso da plataforma Moodle. Em termos de resultados, verificámos que, embora esta plataforma esteja bastante difundida entre nós, o seu uso tem estado essencialmente confinado à complementação das aulas tradicionais, servindo meramente como suporte de informação. Outras utilizações mais ambiciosas da Moodle são ainda extremamente raras, por razões que nós apresentamos e problematizamos.
\end{abstract}

Palavras-chave Moodle, TIC, estratégias de estudo, estratégias de ensino.

Abstract In this paper we analyze the use that is given to Moodle Platform in Portugal. Analyzing what are the more widespread uses of this platform in terms of literature, we confront the use given to it in our country. This study integrates information from one research project with 2674 students and 324 teachers. Both the students and the teachers were interviewed in a deep way about the use they do of the Moodle Platform. In terms of results, we find that although the Moodle Platform is already widespread among us, however, its use is essentially limited to the completion of traditional classes merely serving to put information. Other more ambitious features of Moodle are still extremely rare for reasons that we present and problematize.

$\underline{\text { Keywords }}$ Moodle, ICT, learning strategies, teaching strategies.

Résumé Dans cet article, nous analysons l'utilisation de la plate-forme Moodle au Portugal. Après l'analyse des utilisations les plus répandues de cette plate-forme en termes de littérature, nous sommes confrontés à l'utilisation qui en est faite dans notre pays. Cette étude intègre les données d'un projet de recherche avec 2674 étudiants et 324 enseignants. Les élèves et les enseignants ont été interrogés de manière approfondie sur l'utilisation qu'ils font de la plate-forme Moodle. En termes de résultats, nous constatons que bien que cette plate-forme soit déjà très répandue parmi nous, son utilisation se limite cependant essentiellement à l'achèvement des classes traditionnelles, servant uniquement à garder des informations. D'autres usages plus ambitieux de Moodle sont encore extrêmement rares pour des raisons que l'on présente et problématise par la suite.

Mots-clés Moodle, les TIC, stratégies d'apprentissage, stratégies d'enseignement. 
Resumen Se analiza en este artículo la utilización en Portugal de la plataforma Moodle. En comparación con la literatura, observamos su uso en las escuelas seleccionadas. Este estudio integra la información de un proyecto de investigación con 2674 estudiantes y 324 profesores. Tanto los estudiantes como los profesores fueron entrevistados en profundidad sobre el uso de la plataforma Moodle. En cuanto a los resultados, se encontró que, aunque la plataforma Moodle está muy extendida entre nosotros, su uso se ha limitado principalmente a complementar las clases tradicionales, sirviendo sólo como portador de información. Otros usos más ambiciosos de Moodle son todavía muy raros por razones que presentamos y confrontamos.

Palabras-clave Moodle, las TIC, estrategias de estudio, estrategias de enseñanza.

\section{Introdução}

Os progressos tecnológicos e o desenvolvimento da Internet têm conduzido ao "surgimento de uma sociedade digital marcada por mudanças acentuadas na economia e no mercado de trabalho, impulsionando o nascimento de novos paradigmas e modelos educacionais" (Lisbôa et al., 2009: 44). Focando-nos especificamente no espaço escolar, essa evolução tem vindo a determinar uma crescente implantação das TIC nos processos de ensino-aprendizagem, na gestão escolar, etc. (id., ibid.) ${ }^{1}$

Em Portugal, embora já houvesse algumas tentativas anteriores (essencialmente dispersas) de introdução das TIC nas escolas, podemos situar o dealbar deste processo, de uma forma mais coerente e sistematizada, a partir de finais de 2005, com a publicação do Despacho n. ${ }^{\circ} 16.793 / 2005$, de 3 de agosto, através do qual é formalmente criada a equipa de missão Computadores, Redes e Internet na Escola (CRIE) incumbida de proceder ao desenvolvimento das TIC nas escolas portuguesas (Pimentel, 2009). Mormente, em 2006 a formação de professores no âmbito das TIC foi considerada área prioritária da sua formação contínua. Concomitantemente à referida criação da CRIE, foi também criado um Quadro de Referência para a Formação Contínua de Professores no domínio das TIC (QR-FormProfTIC'06), para dar resposta às necessidades de formação implicadas nas linhas de ação daquela equipa de missão (id., ibid.). No seguimento do trabalho da CRIE foram surgindo "diversos projetos e planos visando a integração das TIC no sistema de ensino português que culminaram, em 2007, com a aprovação do Plano Tecnológico da Educação (PTE)" (Lisbôa et al., 2009: 44). Dois dos eixos estruturantes do PTE "são os conteúdos e a formação, uma vez que se relacionam diretamente com a integração das TIC no processo de aprendizagem" (Bottentuit Junior e Coutinho, 2007: 45). Por sua vez, foi no desenvolvimento do eixo dos conteúdos que o então Ministério da Educação fomentou a generalização do uso dos learning management systems (LMS) e

1 Este artigo decorre de um estudo maior desenvolvido no âmbito do projeto de investigação "Learn-Tech: Tecnologias da Informação e da Comunicação e Aprendizagem" (Ref. PTDC/CS-SOC/102690/2008), desenvolvido no Centro de Investigação e Estudos de Sociologia (CIES-IUL) e tendo como investigador responsável Nuno de Almeida Alves. 
foi nesse sentido que, aliada à vontade de impulsionar a utilização das TIC nas escolas, o ME, por intermédio da Fundação para a Computação Científica Nacional (FCCN) e também do CRIE, disponibilizou a todas as escolas um espaço para alojamento de uma instância Moodle em servidores da FCCN (id., ibid.).

Neste âmbito,

um dos mais populares LMS em Portugal é o Moodle, uma plataforma aberta que os professores podem usar para criar estilos efetivos de aprendizagem online [...] $\mathrm{O}$ Moodle tornou-se atualmente o standard LMS nas escolas públicas da primária ou do secundário e tem sido encorajado mediante projetos governamentais. (Carvalho, Areal e Silva, 2011: 825)

Contudo, apesar de todo este enorme esforço de desenvolvimento dos LMS e, desde logo, da forte implantação e disseminação da Moodle, embora já existam algumas "informações sobre a adoção dos LMS nas escolas e universidades portuguesas, muito pouco se sabe sobre como esses LMS estão a ser usados na prática" (id., ibid.). Por essa razão, uma das preocupações fundamentais da investigação neste âmbito passa por perceber se os LMS, e desde logo a Moodle, estão a ser efetivamente potencializados no processo de ensino-aprendizagem ou se, pelo contrário, constituem apenas repositórios de documentos (Badge, Cann e Scott, 2005; Hall, 2006).

Neste âmbito de investigação, os estudos que têm sido feitos pelo próprio Ministério da Educação indiciam que "o principal uso das LMS em contexto educativo tem sido sobretudo como repositório de conteúdos e não como espaço de colaboração e partilha" (Lisbôa et al., 2009: 45), o que denuncia que "o tipo de uso que é feito das tecnologias é muito redutor em termos do seu verdadeiro potencial" (id., ibid.: 46).

Face ao exposto, pretendemos neste estudo:

1. enquadrar o uso da plataforma Moodle junto do universo de escolas que integraram este projeto de investigação;

2. identificar modalidades de utilização da Moodle junto dos alunos e dos professores do universo de escolas referido em 1;

3. problematizar as principais razões impeditivas (se algumas) de um uso mais ambicioso da Moodle face ao universo de escolas supramencionado.

\section{Fundamentação teórica}

Implementação e desenvolvimento da Moodle em Portugal

Num estudo desenvolvido em duas escolas no Norte de Portugal, Lisbôa et al. (2009: 44) salientam que "a maioria dos professores inquiridos não utiliza a plataforma de apoio à aprendizagem; e que os professores que utilizam a Moodle não o 
fazem tirando partido do potencial que esta plataforma apresenta". Os autores especificam que "a Moodle nas duas escolas analisadas é usada preferencialmente como um repositório de conteúdos digitais e não como um espaço de partilha e colaboração entre os docentes" (id., ibid.: 51). Concordantemente, um estudo de Santos (2012) sobre a utilização da plataforma Moodle num agrupamento de escolas, recorrendo ao cruzamento de diferentes metodologias de observação, enfatiza alguns paradoxos atuais. Por um lado, nas poucas disciplinas em que a Moodle era efetivamente utilizada como ferramenta de ensino-aprendizagem, a sua utilização confinava-se, quase sempre, à disponibilização de informação, reforçando o modelo pedagógico unidirecional e desperdiçando-se o potencial interativo desta plataforma. Além disso, a utilização não pareceu variar consoante a idade dos docentes, e estes tendiam a justificar o uso pouco frequente da Moodle com a falta de formação e, inclusive, o pouco interesse dos alunos. Por outro lado, as taxas de utilização das TIC por parte de docentes e alunos era quase $100 \%$, as taxas de formação dos docentes na plataforma Moodle atingia cerca de $50 \%$ e a adesão dos estudantes a esta ferramenta, quando utilizada, era também genericamente positiva.

Um outro estudo mais recente realizado em dois agrupamentos de escolas portuguesas permite-nos também questionar a importância das lideranças neste processo (Santos e Gaspar, 2014). Embora os resultados deste estudo apontem para o facto de a maioria dos docentes não atribuírem às lideranças um papel decisivo no uso (ou não uso) das tecnologias da informação e da comunicação, uma análise das práticas sugere o contrário. Enquanto num agrupamento de escolas, o diretor e os coordenadores de departamento assumiram a plataforma Moodle como principal via de comunicação com os docentes, no outro agrupamento, embora tendo também a plataforma em funcionamento, isto não ocorreu. Um aspeto interessante é que, no primeiro agrupamento, $42 \%$ dos docentes passaram a comunicar com os estudantes através da Moodle, enquanto no segundo apenas 10\% o fazem (neste caso, é mais comum o contacto com os alunos por e-mail).

Utilizações ambiciosas da Moodle na ligação escola-família. O caso norte-americano

A plataforma Moodle tem uma ampla tradição de funcionamento nos países anglo-saxónicos, nomeadamente nos EUA. Neste âmbito, são de destacar, os "trabalhos de casa interativos" (nomeadamente, os conhecidos TIP - teachers involve parents in schoolwork) (Voorhis, 2003) nos quais a plataforma Moodle constitui o elemento nuclear, ao centralizar uma pluralidade conexa de aplicações e de funções. Um primeiro aspeto decorre da tão demonstrada vantagem da ligação/extensão da estratégia pedagógica dos professores à família (ver, por exemplo; Brophy, 2000; Hirsch, 1998; McDermott e Rothenberg, 2001). Esta ligação é tão mais relevante quanto nos referimos a alunos com menor rendimento escolar (Bryan e Burstein, 2004), nomeadamente, para se desenvolver um duplo feedback de monitorização das dificuldades, dos progressos, etc., desses alunos (Cooper et al., 2001; Voorhis, 2003), e porque os pais, frequentemente, sentem que o tipo de apoio que prestam no cumprimento dos TPC é desapropriado, insuficiente ou, até, errado, havendo 
portanto que convocar a participação do professor através dos chats ou dos fóruns integrantes da plataforma Moodle. Efetivamente, Lee e Heyworth (2000), por exemplo, verificaram que, quando surgem dúvidas ao longo do estudo, alguns alunos mais favorecidos podem ter assistência imediata dos seus pais ou de outros familiares, que atuam como monitores do seu processo de aprendizagem. Contudo, na maioria dos casos, os alunos têm de esperar até à aula seguinte para conseguirem ultrapassar as suas dúvidas mediante o esclarecimento do professor. Uma vez que os "trabalhos de casa" se arvoram sobre conjuntos de conceitos articulados, o facto de alguns deles permanecerem incompreendidos pode determinar a estruturação de um processo de aprendizagem alicerçado sobre bases incorretas. Neste sentido, os chats ou os fóruns podem constituir um instrumento de resposta em tempo razoável ou até imediato (os chamados SOS TPC). Este aspeto é ainda reforçado porque, mesmo para as famílias que podem e pretendem auxiliar os seus filhos, o tempo de apoio disponível tem vindo a diminuir em função das crescentes exigências do mercado de trabalho (Reach e Cooper, 2004). Paralelamente, existem estudos que atestam que os alunos que tendem a fazer um uso mais adequado da referida plataforma são, frequentemente, os que conseguem melhores resultados (Bryan e Burstein, 2004). Neste âmbito, a literatura atesta que, na prática, há pais que facultam tendencialmente mais apoio aos seus filhos do que outros, principalmente em função do nível de instrução detido, sendo os pais com um curso superior (Shumow e Miller, 2001, cit. em Cosden et al., 2004), ou que têm um maior autoconceito quanto à sua capacidade e eficácia (Hoover-Dempsey et al., 2001, cit. em Cosden et al., 2004) os que, com maior probabilidade, auxiliarão os seus filhos a fazer os "trabalhos de casa" e a trabalhar na plataforma Moodle. Por esta razão, urge aprofundar e generalizar o trabalho que é feito com esta plataforma pelos alunos de todas as classes sociais, principalmente os mais desfavorecidos, para os quais esse tipo de apoios é menor e, portanto, previsivelmente haverá um menor aproveitamento das suas potencialidades.

\section{Processos construtivistas de construção do conhecimento através da Moodle}

Se pretendemos que o nosso sistema de ensino continue a ser fundamental no processo de ensino-aprendizagem contemporâneo, urge "compreender o aluno que hoje temos - a chamada geração net - para quem a escola deve ser provedora da informação qualificada, [...] onde a pedagogia da transmissão cede espaço aos processos de cooperação, colaboração, interatividade e diálogo, tendo em vista a construção do conhecimento" (Coutinho e Alves, 2010: 207). É por essa razão que “o 'ensino colaborativo' é uma temática muito valorizada nos últimos tempos [...] e, nesse sentido, muitos sistemas informáticos estão aderindo cada vez mais a essa mais-valia" (Bottentuit Junior e Coutinho, 2007: 51). É o caso da Moodle que, entre outras funcionalidades possíveis, "disponibiliza fóruns eletrónicos que suportam a comunicação e o trabalho colaborativo" (Coutinho e Alves, 2010: 208). Detenhamo-nos nas duas modalidades de comunicação à distância na Moodle - o chat e $\mathrm{o}$ fórum. No primeiro, pela sua natureza síncrona, predominam as comunicações instantâneas ou quase instantâneas, frequentemente pouco aprofundadas ou refletidas 
porque o tempo de reflexão é restrito. Pelo contrário, a natureza assíncrona dos fóruns permite, aos participantes que assim o entendam, a produção de respostas de maior qualidade, porque podem produzi-las em função do tempo necessário para processarem uma reflexão. Assim, o processo de esclarecimento de dúvidas é, desde logo, uma das virtudes da Moodle que, por exemplo, possibilita que através de fóruns os alunos vão, entre si, problematizando os assuntos, podendo até estas trocas de informações constituir-se como elevados momentos de aprendizagem (Cunha e Paiva, 2003; Freitas, 1997; Novak e Gowin, 1996; Perrenoud, 2002), porque as explicações de aluno para aluno tendem a ser mais acessíveis, dada a proximidade conceptual dos alunos entre si (Champagne e Bunce, 1991), facultando uma aprendizagem "que nasce do confronto dos conhecimentos de cada um com os conhecimentos dos colegas, gerando um desequilíbrio cognitivo que proporciona uma reflexão mais profunda e o emergir de aprendizagens mais sustentadas" (Coutinho e Alves, 2010: 212). Por esta razão, "uma das principais características da nova Web é o facto de os utilizadores, que antes tinham um papel passivo, poderem agora produzir conteúdos" (Simão, 2006). Mormente, este aspeto da construção de conhecimento via fóruns deve ser merecedor de especial acuidade, dado que esta troca e partilha de informações online com o professor ou com os colegas tende a tornar os cursos mais fáceis e motivantes (Garrido, 2008).

Estas diferentes perspetivas convergem para os princípios da aprendizagem cooperativa e do construtivismo. Os alunos ao desenvolverem, através da Internet, o seu trabalho de pesquisa de informação podem, também eles, gerar informação, o que, associado ao facto de, por norma, poderem controlar o seu progresso em termos de aprendizagem, implica vantagens sociocognitivas inerentes (Monereo, 2005).

\section{Limitações a uma implementação mais ambiciosa da Moodle em Portugal}

O que mais se destaca na adoção educativa das TIC e da Internet nas escolas portuguesas é uma quase centração das entidades oficiais na aquisição de equipamentos e na proliferação de programas de formação de professores onde prevalece a vertente técnica do domínio das TIC em detrimento da sua utilização pedagógica nos diferentes níveis e modalidades de ensino e formação (Brito, Duarte e Baía, 2004). Desta forma, a preparação dos professores para usar as TIC não tem sido uma prioridade educativa proporcional ao equipamento das escolas com infraestruturas informáticas, deixando transparecer a ideia errada de que a introdução do computador e da Internet pode resolver muitos dos problemas do ensino e da aprendizagem (Alves, 2008; Piano, 2007). Ora há que ter em conta que "não é a simples introdução do computador na escola que vai provocar uma mudança efetiva" (Alves, 2008; Piano, 2007; Silva, 2005). Assim, "o denominador comum às diferentes barreiras que impedem a integração das TIC em contexto educativo é a falta de formação dos professores, tanto ao nível da formação inicial como contínua" (Lisbôa et al., 2009: 46). No que respeita à formação inicial, Costa et al. (2008) referem como fator determinante a insuficiente preparação recebida nas instituições responsáveis pela formação, confinada, maioritariamente, à aprendizagem das tecnologias sem perspetivar uma utilização integrada nas atividades 
curriculares, havendo muito poucas ações de formação para disciplinas específicas (Paiva, 2002).

Uma outra questão limitativa da implementação da Moodle prende-se com o tempo necessário para gerir o trabalho na plataforma: "Apesar do reconhecimento das potencialidades da Moodle os docentes indicam que o recurso à Moodle exige demasiado tempo para a preparação das atividades letivas e afirmam, ainda, sentir algum desconforto na interação com esta tecnologia" (Lisbôa et al., 2009: 54), que resulta, por sua vez, na maioria dos casos, da sua insuficiente preparação, como referimos atrás.

\section{Metodologia}

Amostra

A amostra que serviu de base a este estudo foi composta por 2674 alunos, 324 professores e 12 diretores e/ou responsáveis das 12 escolas observadas. Tratou-se de uma amostra não probabilística, procurando apenas assegurar alguma diversidade territorial, social e educativa dos respondentes (em termos de formação de base e disciplinas ministradas pelos professores, cursos científico-humanísticos e anos curriculares frequentados pela população discente). A amostra compreendeu apenas os cursos científicos-humanísticos/gerais do ensino público, de acordo com os objetivos do projeto de investigação. A não inclusão das vias profissionalizantes (cursos tecnológicos, ensino artístico e cursos profissionais) neste segmento etário na amostra do inquérito não implicou uma desconsideração por esta via de ensino mas, antes, procurou evitar a enorme complexidade que a grande diversidade destas modalidades de ensino implicaria no desenho da amostra. A restante oferta formativa do ensino secundário, nomeadamente os cursos de educação e formação (CEF), educação e formação de adultos (EFA) e os processos de validação, reconhecimento e certificação de competências (RVCC), foram também excluídos da amostra por razões de limite etário e de trajeto formativo da respetiva população discente. É certo que com estas restrições acabámos por remeter a população alvo deste projeto de investigação para um pouco mais de $50 \%$ do total de matriculados no ensino secundário, segundo os dados do ano letivo de 2008/2009: 173.591 contra 329.137 alunos (GEPE, 2010: 77). Contudo, tais opções conduziram-nos a uma amostra mais homogénea em termos etários e de enquadramento educativo, com vantagens evidentes em termos de fiabilidade de resultados e de contenção de custos de operacionalização.

Procurando seguir os mesmos critérios de diversidade geográfica e de área disciplinar, foram selecionados 13 professores e 13 alunos, de cinco das 12 escolas, onde foi aplicado o inquérito por questionário, para responderem a uma entrevista. 


\section{Plano de observação}

A primeira fase de inquirição consistiu no desenvolvimento de um processo de inquérito composto por três guiões de questionário semiestruturado (autónomos) destinados a cada um desses três segmentos de atores referidos (alunos, professores e diretores). O inquérito aplicado teve como propósito a recolha de dados quantitativos de caracterização do uso das TIC. Paralelamente, por forma a investigarmos relações mais recônditas ligadas ao referido uso que, com grande probabilidade, seriam dificilmente percecionáveis através da passagem desses questionários, complementámos a informação mediante a aplicação de 26 entrevistas em profundidade a alunos e a docentes. Os resultados combinarão, portanto, dados qualitativos e quantitativos.

\section{Modelo de análise}

Dada a natureza das variáveis tratadas nos questionários (escalas nominais e ordinais), procurámos construir modelos de análise multivariada através da análise log-linear. Os padrões de relações identificados (de 1. ${ }^{\mathrm{a}}, 2 .^{\mathrm{a}}$ ou $3 .^{\mathrm{a}}$ ordem) foram depois analisados através de outros testes bivariados e multivariados mais simples, para aprofundar a natureza dessas relações encontradas, seguindo um procedimento próximo dos propostos por Hagenaars (1994) e Knoke e Burke (1991). Paralelamente, desenvolvemos uma análise de conteúdo simples para tratar a informação das entrevistas.

\section{Resultados}

Contextualização do uso da plataforma Moodle junto do universo de escolas do estudo

A perceção que os alunos têm da indispensabilidade de saber usar computadores e a Internet para arranjar um bom emprego no futuro surgiu a condicionar tanto o uso do computador e da Internet feito dentro da escola fora das aulas (no qual se inscreve a utilização da Moodle), como esse mesmo uso feito fora desta (no qual também se enquadra o uso da Moodle). Verificámos que essa perceção é mais acentuada para os alunos de ciências económicas $(67,3 \%)$, seguidos dos seus colegas de Línguas e Humanidades (62,1\%), de Ciências e Tecnologias (58,0\%) e, por fim, dos colegas de Artes Visuais $(48,5 \%)\left(\chi^{2}=56.228, \mathrm{p}<0,001\right.$ e V =0,10). Trata-se de uma motivação extrínseca para o uso das tecnologias cuja relevância tem sido sublinhada em estudos internacionais como sendo um fator fundamental para condicionar o uso que as crianças e principalmente os jovens fazem das novas tecnologias (OECD, 2004). Mormente, esta perceção tende a acentuar-se, embora com pouca intensidade, na passagem do $10 .^{\circ}$ para o $12 .{ }^{\circ}$ ano, independentemente do curso frequentado $\left(\chi^{2}=23.821, p<0,001\right.$ e $\left.V=0,15\right)$.

Por sua vez, a frequência de utilização dos computadores e da Internet nas salas de aula condiciona, embora com fraca intensidade $\left(\chi^{2}=33.164, p<0,001\right.$ e 
$V=0,29)$, o uso que os alunos fazem das TIC na escola fora das aulas. Contudo, o uso de computadores e Internet fora da escola não surge associado à frequência de uso nas aulas (exceto a Moodle, como veremos seguidamente) $\left(\chi^{2}=1.097, p>0,05\right)$, o que, pelo menos em parte, indicia que o uso do computador e da Internet na escola embora fora das aulas é, ainda assim, parcialmente instrumental e/ou decorrente da lógica de utilização nas aulas (é um uso frequentemente escolar, em suma) enquanto o uso das TIC fora da escola segue um padrão de influência independente do uso escolar, exceto para o cumprimento da estratégia de estudo que é, digamos assim, um prolongamento da escola para fora do seu domínio físico de influência (daí o uso da Moodle ser influenciado em ambos os contextos, como veremos adiante com maior detalhe). O espaço escolar marca assim uma certa afetação ubíqua das TIC às atividades educativas na escola. Contudo, complementarmente, a análise multivariada permitiu ainda perceber que a utilização de computadores e Internet na escola fora das aulas é também influenciada pela frequência do uso de computadores e Internet fora da escola. Da conjugação destes dois níveis de influência em simultâneo percebe-se que, no essencial, a estratégia de uso das TIC na escola fora das aulas por parte dos alunos compõe-se e estrutura-se segundo a complementaridade de duas práticas com campos de influência determinados, que exercem a sua ação inclusivamente fora dos seus domínios de influência física: as funcionalidades formativas das TIC surgem condicionadas ao uso escolar (nomeadamente decorrente das dinâmicas pedagógicas de sala de aula) e prolongam-se na escola fora das aulas e fora da escola - efeito socialização escolar das TIC; de igual modo, as funcionalidades não formativas surgem condicionadas por um padrão de uso mais genérico que tanto opera na escola fora das aulas como fora da escola - efeito outras socializações das TIC.

Focalizando-nos agora na Moodle (ver quadro 1), verifica-se que, tanto para o uso de computador e Internet dentro da escola fora de aulas, como para o seu uso fora da escola, a utilização da Moodle aparece com valores extremamente baixos: dentro da escola fora das aulas as categorias "nunca" ou "pouco frequentemente" são referidas em $84,2 \%$ dos casos; fora da escola, as categorias "nunca" ou "algumas vezes por mês" predominam, com $62 \%$ das respostas.

Procurámos averiguar até que ponto o tempo de utilização da Internet nos dias de uso, bem como os anos de utilização da Internet influenciavam, ou não, por sua vez, estes dois padrões de utilização da Moodle. Verificámos que são os alunos que menos tempo estão na Internet os que mais tempo dedicam à Moodle. Paralelamente, verificámos, também, que são os alunos que há comparativamente menos anos trabalham na Internet os que mais tempo dedicam ao uso da Moodle: prevalecem os alunos dos anos iniciais (10.. ano face ao $\left.12 .{ }^{\circ}\right)$, embora mediante uma relação significativa mas com fraca intensidade $\left(\chi^{2}=67.113, \mathrm{p}<0,001 \mathrm{eV}=0,12\right)$. Pelo contrário, os utilizadores mais experimentados e que navegam durante mais tempo usam as TIC fundamentalmente para atividades de tipo não formativo, pelo que, para este grupo, em média, o uso da Moodle é essencialmente residual.

Verifica-se ainda que o uso da Moodle por parte dos alunos, quer na escola fora das aulas quer fora da escola, se integra na lógica mais global de uso das TIC. Este uso na escola fora das aulas compõe-se, essencialmente, em dois tipos (identificados 
Quadro 1 Utilização da plataforma Moodle

\begin{tabular}{|c|c|c|c|c|c|c|c|}
\hline \multicolumn{4}{|c|}{$\begin{array}{l}\text { Uso do computador e da Internet na escola fora } \\
\text { das aulas }\end{array}$} & \multicolumn{4}{|c|}{ Uso do computador e da Internet fora da escola } \\
\hline \multicolumn{4}{|c|}{$\begin{array}{c}\text { Consultar a plataforma Moodle para procurar fichas } \\
\text { e exercícios das disciplinas }\end{array}$} & \multicolumn{4}{|c|}{$\begin{array}{c}\text { Fazer trabalhos e exercícios disponibilizados na Moodle } \\
\text { ou noutras páginas eletrónicas }\end{array}$} \\
\hline & $\mathrm{N}$ & $\%$ & $\begin{array}{c}\% \\
\text { válida }\end{array}$ & & $\mathrm{N}$ & $\%$ & $\begin{array}{c}\% \\
\text { válida }\end{array}$ \\
\hline Nunca & 682 & 25,5 & 55,5 & Nunca & 848 & 31,7 & 32,4 \\
\hline $\begin{array}{l}\text { Pouco } \\
\text { frequente }\end{array}$ & 353 & 13,2 & 28,7 & $\begin{array}{l}\text { Algumas vezes } \\
\text { por mês }\end{array}$ & 776 & 29,0 & 29,6 \\
\hline Frequente & 151 & 5,6 & 12,3 & $\begin{array}{l}\text { Sobretudo ao fim } \\
\text { de semana }\end{array}$ & 378 & 14,1 & 14,4 \\
\hline \multirow[t]{2}{*}{$\begin{array}{l}\text { Muito } \\
\text { frequente }\end{array}$} & 43 & 1,6 & 3,5 & $\begin{array}{l}\text { Algumas vezes } \\
\text { por semana }\end{array}$ & 541 & 20,2 & 20,7 \\
\hline & & & & $\begin{array}{l}\text { Todos os dias } \\
\text { ou quase }\end{array}$ & 76 & 2,8 & 2,9 \\
\hline Total & 1229 & 46,0 & 100,0 & Total & 2619 & 97,9 & 100,0 \\
\hline \multirow[t]{2}{*}{ NS/NR } & 1445 & 54,1 & & NS/NR & 55 & 2,1 & \\
\hline & 2674 & 100,0 & & & 2674 & 100,0 & \\
\hline
\end{tabular}

por análise fatorial): um primeiro tipo que designámos como não formativo, onde se integram um conjunto de práticas diversificadas, desde o "visionamento de páginas de desporto", à "comunicação com os amigos pelo e-mail", passando pela "prática de jogos com amigos", etc. (com 40,1\% da variância); um segundo tipo que, por ser eminentemente escolar, classificámos como formativo, no qual a Moodle surge integrada no âmbito das seguintes variáveis: "fazer trabalhos de casa", "pesquisar informações, imagens ou outras coisas para os meus trabalhos", "fazer trabalhos de grupo em conjunto com os meus colegas", "usar o correio eletrónico para comunicar com os professores, expor dúvidas, receber esclarecimentos e/ou enviar trabalhos" e "consultar a plataforma Moodle para procurar fichas e exercícios das minhas disciplinas" (com $12,8 \%$ da variância). Paralelamente, o padrão de uso das TIC fora da escola é mais complexo, essencialmente devido ao surgimento de várias subdimensões de uso correspondentes ao primeiro eixo não formativo que vimos antes. Assim, definem-se neste caso cinco padrões de utilização das TIC (também por análise fatorial): Um primeiro eixo (com 29\% da variância), que designámos "pesquisa de sites e visionamentos não formativos"; o segundo (com $11 \%$ da variância) que classificámos como "aquisições pela Net" (descarregar músicas, filmes, fazer compras, etc.); um terceiro eixo (com $9 \%$ da variância) que designámos "interações pela Net", que se processam, nomeadamente, através das redes sociais; um quarto eixo (com 7\% da variância) que designámos "jogos pela Net"; e, finalmente, um quinto eixo, que surge associado a atividades propriamente escolares e/ou formativas, que classificámos, por isso, "eixo de formação" (com apenas 6\% da variância), o que mostra bem até que ponto este tipo de atividades formativas são as menos valorizadas 
pelos alunos no amplo âmbito da sua utilização das TIC. Neste último eixo surgem associadas as seguintes variáveis: "fazer trabalhos e exercícios disponibilizados na Moodle ou noutras páginas eletrónicas"; "procurar e consultar sítios Web específicos sobre temas relacionados com as minhas disciplinas escolares" e, finalmente, "receber e enviar correio eletrónico". Veja-se que a variância respeitante às utilizações de formação na escola fora das aulas $(12,8 \%)$ é mais do dobro da congénere fora da escola (6\%), acentuando a zona de influência escolar sobre as atividades TIC de natureza formativa desenvolvidas dentro da escola, como tínhamos visto atrás.

Além disso, verifica-se uma associação média entre fazer trabalhos e exercícios disponibilizados na Moodle fora da escola e a utilização desta mesma plataforma na escola fora do tempo de aulas $\left(\chi^{2}=195.096, p<0,001\right.$ e $\left.V=0,40\right)$, o que faz perceber - aprofundando relações que referimos atrás - que o uso desta plataforma é a prática mais generalizada da estratégia de estudo dos alunos, cortando, por isso, transversalmente, os diversos contextos nos quais o aluno se move: os alunos que na escola fora das aulas nunca ou raramente recorrem à Moodle são, na sua maioria $(77,8 \%)$, os que também nunca ou raramente fazem exercícios disponibilizados na Moodle ou noutras páginas fora da escola; inversamente, são os alunos que mais frequentemente fazem exercícios na Moodle na escola fora das aulas os que mais referem fazê-lo noutros contextos.

Mormente, a frequência de utilização dos computadores e da Internet nas aulas surge duplamente associada, por um lado, ao uso que os alunos fazem da Moodle na escola fora das aulas e, por outro, ao uso da Moodle noutros contextos, evidenciando (paralelamente à questão da influência da escola para além do seu espaço físico que vimos atrás) até que ponto a utilização das TIC, e especificamente da Moodle, é uma atividade socializada dos alunos sendo, por isso, influenciada pelo uso que os diferentes professores dela fazem $\left(\chi^{2}=273.117, p<0,001 \mathrm{eV}=0,63\right)$. A reforçar esta tendência, o uso da Moodle surgiu também associado à "troca de mensagens com o professor" e à "utilização de software educativo específico indicado por ele" $\left(\chi^{2}=399.777, \mathrm{p}<0,001 \mathrm{e} \mathrm{V}=0,57\right)$, emergindo, portanto, como um dos indicadores de um padrão mais complexo na relação que os alunos estabelecem com determinado tipo de professores. Efetivamente, verifica-se, tendencialmente, um padrão aglutinador: os professores que mais usam as TIC e que mais incentivam o uso da Moodle e fazem dela uma utilização mais consistente são, também, aqueles cujos respetivos alunos mais trocam mensagens eletrónicas com eles, que mais usam os web sites por eles recomendados e que mais se envolvem na plataforma Moodle, passando-se o inverso com o perfil oposto de professor. Este padrão essencialmente maioritário permite, com alguma segurança, indicar que o uso da Moodle na escola por parte dos alunos decorre da lógica de uso que os professores dela fizerem, havendo docentes que, como se disse, por terem uma prática consistente, envolvem os alunos e estes participam e, inversamente, professores que não usam e levam os alunos a não o fazer também, indo assim ao encontro do que nos propõe Hinson (2005), que verificou que a utilização escolar das TIC pelos alunos é fortemente condicionada pelo uso que os respetivos professores delas fazem. Neste sentido, embora haja um padrão de uso mais elevado para certas unidades 
curriculares, em todas elas há elevados padrões de uso e de não uso, remetendo a questão, todavia, não para a natureza da disciplina mas para o perfil do professor e, desde logo, para a sua preparação e/ou atitude face às TIC. Vejamos, exemplificando com os valores de seis das unidades curriculares. Aquelas onde os alunos referiram que a frequência média de uso do computador e Internet na sala de aula foi mais elevada foram Geografia/Geologia (2,09), Oficina de Artes e Oficina Multimédia $(2,03)$ e Biologia $(1,96)$; pelo contrário, onde foi referido um uso menos frequente foi em Matemática/Matemática ACS $(1,50)$, Física $(1,51)$ e Geometria Descritiva/Desenho $(1,51)$. Tal distribuição, à primeira vista, poderia indicar que existe um uso diferencial segundo as diversas unidades curriculares em função dos assuntos tratados e, concomitantemente, da existência, ou não, de sites com informação disponível. Se tal é essencialmente verdade para Matemática, ainda assim os dados indicam-nos que o padrão de utilização das TIC por unidade curricular depende mais do perfil do professor que a leciona do que da natureza intrínseca dos assuntos abordados. De facto, verificámos as mesmas justificações para usar (ou não usar) as TIC para professores de unidades curriculares muito diferentes: por exemplo, há inúmeros docentes de Geografia/Geologia que nunca usam, assim como há diversos colegas seus de Matemática que recorrem às TIC com grande frequência. Assim, a utilização das TIC segundo as diversas unidades curriculares que vimos atrás define padrões tendenciais de uso, mas o que mais definitivamente parece determinar o recurso às TIC, em geral, e à Moodle em particular, enquanto estratégia pedagógica, é o facto de o perfil do professor ser mais ou menos favorável ao uso dessa tecnologia. Um dos docentes entrevistados refere-se a esta questão nestes termos:

[...] Vai da predisposição das pessoas para estas coisas, há quem tenha uma apetência natural e até goste, e outras para as quais isto é um pavor e mesmo aquelas coisas básicas como copiar um ficheiro para outro, é um bicho de sete cabeças. [Professor de Biologia, 36 anos].

Neste âmbito, à primeira vista, poderia parecer que seriam os alunos que tendem a apreciar de forma mais positiva a utilização de computadores na sala de aula, por exemplo aqueles que dizem que "as aulas são mais interessantes quando usamos computadores e Internet", os que, por correspondência, mais utilizariam a Moodle enquanto instrumento de apoio, exatamente por se tratar também de um suporte eletrónico. Porém, a correlação revelou-se não significativa $\left(\chi^{2}=19.757, \mathrm{p}>0,05\right)$. Estes alunos são, na verdade, estudantes que recorrem muito ao uso das TIC mas, fundamentalmente, para os fins lúdicos que referimos atrás. Paralelamente, são tendencialmente os alunos que indicaram maior concordância com a afirmação "por vezes quando utilizamos computadores e Internet nas aulas é mais difícil acompanhar a matéria" os que menos recorrem ao uso da Moodle, embora mediante uma relação de fraca intensidade $\left(\chi^{2}=25.346, \mathrm{p}<0,05 \mathrm{e} \mathrm{V}=0,20\right)$.

Também os cursos frequentados condicionam o uso que os alunos fazem da Moodle na escola fora das aulas ou fora da escola. De facto, a percentagem de alunos que afirmam usar a Moodle "sempre" ou "quase sempre" na escola fora 
das aulas é a seguinte: Ciências e Tecnologias: 40,8\%; Ciências Económicas: 16,8\%; Línguas e Humanidades: 14,1\%; Artes Visuais: 28,3\% - definindo-se diferenças estatisticamente significativas destes utilizadores por curso de pertença $\left(\chi^{2}=19.654, \mathrm{p}<0,001 \mathrm{e} \mathrm{V}=0,13\right)$. Além disso, como já dissemos, em todos os cursos predomina o uso junto dos alunos dos anos mais iniciais, à exceção de Artes, onde predomina o uso no $12 .^{\circ}$ ano, fazendo avultar a natureza dos assuntos tratados.

Concomitantemente, os níveis de frequência mais elevados para fazer trabalhos e exercícios disponibilizados na Moodle fora da escola descrevem um padrão próximo desse: Ciências e Tecnologias: 31,2\%; Ciências Económicas: 18,8\%; Línguas e Humanidades: 20,3\%; Artes Visuais: 21,6\% ( $\chi^{2}=37.563, p<0,05$ e V = 0,12). Uma vez mais se percebe que a própria natureza do curso condiciona o uso não escolar das TIC em geral e da Moodle em particular. Desde logo, tal percebe-se pois, como vimos, o uso da Moodle é também condicionado pela frequência de uso em sala de aula e a composição relativa dos cursos pelas diversas unidades curriculares varia em função da sua natureza, devido à especificidades dos respetivos planos de estudos (embora, fundamentalmente, como também já se viu, se deva ao perfil de cada professor ser mais ou menos favorável à implementação das TIC no âmbito da sua estratégia pedagógica).

Modalidades de utilização da Moodle por parte dos alunos e dos professores das escolas estudadas

A grande generalidade das funcionalidades da Moodle descritas na literatura são usadas de uma forma extremamente parca no âmbito das escolas inquiridas (ver quadro 2). A única funcionalidade da Moodle que aparece mais explorada (mas, ainda assim com, no máximo, $60 \%$ de menções) é a colocação de matéria e/ou apontamentos. A Moodle aparece, portanto, essencialmente centrada no ensino tradicional, servindo como complementação dessa atividade, mas raramente surgindo associada a utilizações mais ambiciosas.

Uma outra utilização bastante referida é o recurso ao e-mail que, embora não seja uma das funcionalidades da Moodle, é frequentemente usado como alternativa quer à colocação de informação que referimos atrás, quer aos fóruns que analisaremos adiante. Ora, algumas das funções que os professores usam com o $e$-mail são atualmente muito mais eficazes através da Moodle. Percebe-se que há aqui, portanto, uma perda importante de eficácia didática porque, ao não saberem usar a plataforma ou ao usarem-na aquém daquilo que ela pode dar, certas dimensões didáticas não chegam a ser exploradas, o que remete para a importância de, na formação de professores, passar a incluir-se uma formação específica neste âmbito.

Em termos de utilizações mais ambiciosas, foi-nos referido apenas uma vez a conjugação da Moodle com o quadro interativo, permitindo guardar apresentações já feitas, às quais se podem ir acrescentando melhorias, otimizando-as didaticamente. Esta vertente de poder guardar uma apresentação permitindo enviá-la para a Moodle faculta, por exemplo para um aluno que não pôde ir à aula, uma evidente mais-valia, porque ele pode ver em diferido uma explicação já feita sem perder o que foi dado. 
Quadro 2 Frequência de uso das principais funcionalidades da Moodle

\begin{tabular}{l|l|l}
\hline \multicolumn{2}{l|}{ Exercícios online } & Extremamente infrequente (0\% a 1\%) \\
\hline \multirow{2}{*}{ Colocação de matéria / apontamentos / power points } & Frequente (de 10\% a 60\%) \\
\hline \multirow{3}{*}{ Anexos } & Textos & Infrequente (de 5\% a 10\%) \\
\cline { 2 - 3 } & Livros & Muito infrequente (de 1\% a 5\%) \\
\cline { 2 - 3 } & Filmes/vídeos & Extremamente infrequente (0\% a 1\%) \\
\hline Colocação de sumários & Aluno-aluno & Extremamente infrequente (0\% a 1\%) \\
\cline { 2 - 3 } Chats/fóruns na Moodle & Aluno-professor & Infrequente (de 5\% a 10\%) \\
\cline { 2 - 3 } & Professor-professor & Infrequente (de 5\% a 10\%) \\
\cline { 2 - 3 } & Professor-famílias (vice-versa) & Muito infrequente (de 1\% a 5\%) \\
\hline
\end{tabular}

Trata-se de uma funcionalidade de E-learning em que o aluno acede desde sua casa, através da Moodle, à apresentação da aula, e fá-lo no momento que mais lhe aprouver (modalidade assíncrona). Além disso, ao estar guardada a apresentação, ela pode ser consultada tantas vezes quantas se pretender. Acaba por acontecer aqui aquilo que Férres (2004) apresenta como sendo uma das incontestáveis vantagens das apresentações em vídeo face às aulas tradicionais: os conteúdos cuja compreensão possa ser mais difícil e, portanto, impliquem maior tempo de aprendizagem académica, podem ser sucessivamente repetidos até à sua cabal compreensão. A escola do Academic Learning Time (ver, por exemplo, Shulman, 1989) tem amplamente demonstrado a relevância de centrar os tempos de explicação nos ritmos próprios dos alunos. Estes tempos nem sempre são semelhantes para todos os alunos e para os diversos conteúdos programáticos. Ora, a possibilidade de guardar apresentações das aulas para a sua posterior disponibilização na plataforma Moodle consegue constituir-se como uma estratégia vantajosa, porque permite que os diversos alunos, posteriormente, em diferido (e ao seu ritmo), acedam a esses materiais tantas vezes quantas as necessárias até à cabal compreensão do fenómeno ou do conceito em estudo.

Ainda em termos das utilizações mais ambiciosas, foi-nos referida, embora novamente apenas uma única vez, uma prática de ensino interativo à distância mediante o uso do $e$-mail (note-se que, mais uma vez, este trabalho poderia ser feito na Moodle - via chat) (ligação professor-aluno e vice-versa), essencialmente para dar resposta eficaz ao estudo dos alunos em casa ou ao cumprimento dos TPC (mediante uma metodologia próxima dos SOS Homework norte americanos):

Vamos falando quando é necessário. Nesta altura de exames nacionais o meu e-mail está aberto $24 \mathrm{~h}$ sobre $24 \mathrm{e}$ eles expõem as suas dúvidas eletronicamente. [Professor de Biologia, 36 anos]

Trata-se de uma situação que implica um procedimento síncrono ou, pelo menos, com feedback muito rápido para poder ser eficaz. Neste sentido, uma das alunas, por exemplo, refere que 
Este ano não gosto [da Moodle]. Nunca está lá ninguém. [...] [No ano passado] a professora estava sempre lá, quase sempre online, falava connosco, se eu tivesse alguma dúvida, a professora esclarecia dentro de uma hora, ou duas, era eficiente. [Aluna do 11. o ano de Línguas e Humanidades, 16 anos]

Trata-se de uma prática evidentemente proveitosa, porque permite ultrapassar imediatamente dúvidas que podem dificultar a continuação do estudo autónomo ou em grupo (via chat, que é síncrono, ou via fórum, que é assíncrono). Comparativamente, cabe referir que, no e-mail, esta troca de informações, sendo possível, é porém descontínua: eu recebo, leio, respondo, envio, perdendo-se o fio sequencial se, entretanto, outros procurarem entrar na troca de informações em simultâneo. Além disso, se se pretender anexar muita informação aos e-mails (principalmente, com formatos mais pesados, como vídeos, filmes, etc.) os diversos servidores do correio eletrónico raramente disponibilizam "espaço" suficiente para tanta informação, o que implica enviar esses anexos em várias mensagens ou compactá-las através de compactadores adequados, o que, em qualquer dos casos, dificulta estas tarefas, conduzindo a elevadas perdas de tempo e tornando-as ineficazes.

Esta gestão da aprendizagem fora de aula em regime interativo permite, através do chat ou do fórum, consoante os casos, responder a inúmeras dúvidas que vão surgindo, permitindo o prosseguimento do estudo. Contudo, nem sempre esta solução pode dar resposta a todos os níveis de questões. Nalguns casos, a natureza das dúvidas ou dos assuntos exige um contacto presencial professor-alunos. Por este facto, um dos docentes inquiridos afirma que "quando eu noto que não consigo, eletronicamente, resolver a situação, combinamos um encontro e conversamos" [professor de Biologia, 36 anos]. Desde logo, há que ter em conta que é mais fácil falar do que escrever. Por isso, os utilizadores da Moodle tendem a encurtar ao máximo as exposições ou explicações apresentadas, eventualmente omitindo partes importantes, o que pode dificultar a compreensão de um assunto:

Isso obriga a estar aqui no teclado a escrever, na conversa com alguém. É uma das coisas que eu não sou capaz de fazer. [...] Se fosse possível falar pelo microfone, ainda vá que não vá. Agora, eu não escrevo. Eu gosto de escrever as palavrinhas todas em português, com todos os acentos. [Professor de Sociologia, 53 anos]

Esta mesma gestão da escrita leva um dos alunos entrevistados a afirmar que

[...] Há a transmissão de conhecimentos, mas é tudo um bocado sintetizado, é um bocado por tópicos e nunca é igual a uma aula. [...] Há sempre uma parte de fundo que não está lá. [Aluno do 12.ํ ano de Línguas e Humanidades, 18 anos]

Seja como for, se a maioria das situações puderem ser resolvidas através da plataforma Moodle, como parece ser o caso, então só sobram para estes encontros face a face situações excecionais, o que, desde logo, facilita muitíssimo quer o trabalho do professor, quer dos alunos, que só excecionalmente têm de sair das suas casas e interromper o sequenciamento das suas atividades para um encontro. 
Uma outra virtualidade adstrita ao uso do fórum da plataforma Moodle é a possibilidade de os professores contactarem as famílias dos alunos (ligação professor-famílias). Trata-se de uma prática muito desenvolvida nos EUA, através da qual se procura minorar os tão frequentes fossos que tendem a estabelecer-se entre a escola e as famílias dos alunos, desde logo em termos da resolução dos TPC, durante os quais podem surgir dúvidas nas quais os professores podem auxiliar as famílias desde que esta funcionalidade esteja disponível e seja usada. Na nossa amostra esta modalidade de uso não foi referida uma única vez enquanto prática atual.

Paralelamente, uma outra virtualidade ligada a esta refere-se à utilização da Moodle, uma vez mais através dos chats ou dos fóruns, para contactar os colegas (ligação professor-professor). Para além de poder ser um espaço para acertar detalhes administrativos e burocráticos da gestão escolar, esta virtualidade permite a troca de informação científica e pedagógica entre os docentes. Aparecem, contudo, também, muito poucas referências a esta modalidade, que é principalmente usada apenas para fins burocráticos:

O nosso grupo aqui na escola é extremamente individualista e neste momento não tem uma dinâmica que devia de ter, [...] de modo que é mais informalmente que se vai perguntando àqueles colegas com os quais temos mais comunicação: “O que é que estás a fazer?" [Professora de Filosofia, 50 anos]

Principais razões impeditivas de um uso mais ambicioso da Moodle no âmbito das escolas estudadas.

Como acabámos de ver, existe ainda pouca proficiência no uso de algumas das potencialidades da Moodle, nomeadamente, do chat ou do fórum. Neste âmbito, cabe referir que o facto de os alunos utilizarem o chat no Facebook mostra, pelo contrário, que não se trata, pelo menos da sua parte, de um desconhecimento total do funcionamento deste tipo de funções eletrónicas. Não existe é ainda socializada entre nós uma prática de utilização dessas funcionalidades na escola, principalmente porque alguns professores - por não dominarem as competências necessárias à sua utilização, por falta de tempo, por dificuldades técnicas ou, até, por impedimentos do lado dos alunos - , alternativamente recorrem ao e-mail que está muito mais divulgado e implantado entre nós.

Cruzam-se aqui aspetos institucionais com outros mais idiossincráticos do professor (motivacionais, por exemplo) e da natureza das próprias unidades curriculares, como já vimos anteriormente. Na verdade, uma percentagem não negligenciável de docentes referiu nas entrevistas que não usa a Moodle porque não é detentor do know how necessário para o fazer de uma forma eficaz, enfatizando, por isso, que seriam necessárias ações de formação para adquirir o conjunto de conhecimentos necessário, para só então poder usar as TIC em geral e a Moodle em particular. Ora, neste âmbito é de referir que os diretores de escola se pronunciaram de forma maioritariamente favorável face à afirmação: "é fundamental que a escola proceda a uma progressiva integração dos computadores e da Internet no ensino, 
em sala de aula, de todas as disciplinas do currículo" (58,3\% disseram concordar totalmente, 33,3\% disseram concordar parcialmente, e apenas 8,3\% afirmaram discordar totalmente). Além disso, a quase totalidade deles (91,7\%) afirmaram que "existe um plano ou estratégia educativa específica, por parte da escola, com vista à incorporação dos computadores e da Internet no processo de ensino-aprendizagem". No entanto, é ao pedir para especificar as ações que constam dessas estratégias que se percebe o problema: enquanto a generalidade dos docentes inquiridos enfatiza a urgência de fazer mais ações de formação em TIC, para os professores em geral e sobre a Moodle em particular, as direções das escolas, pelo contrário, apenas referem como prioridade de intervenção esse tipo de ações em 16,7\% dos casos, situando-se a quase totalidade das suas preocupações na "melhoria das condições técnicas já existentes" e no "aumento do número de equipamentos", mesmo nas escolas nas quais nós, por cruzamento de dados, verificámos que estão já bastante apetrechadas. Percebe-se assim que as políticas da generalidade das escolas estudadas face às TIC estão essencialmente desajustadas em relação àquilo que são as reais necessidades sentidas nesse âmbito, ficando, por isso, os docentes essencialmente entregues a si próprios face às formações necessárias e à dinâmica global de implementação efetiva das TIC nas suas unidades curriculares, desenvolvendo-se uma estratégia essencialmente informal de aproveitamento daquelas em cada escola. Esta contradição entre os desideratos dos docentes e dos diretores surgiu amplamente representada ao longo das nossas entrevistas. Vejamos brevemente alguns exemplos esclarecedores:

[...] Na nossa disciplina, não tivemos muito apoio para isso. Sei que há escolas em que vai tudo para a plataforma, o que eu acho ótimo, mas nós aqui, na Física e na Química, não houve incentivo nesse aspeto. [...] Em termos de computadores, temos muitos, isso aí temos. Em termos de apoio, para mim, essa lacuna da plataforma Moodle, não temos uma pessoa aqui. [Professora de Físico-Química, 58 anos].

Outro professor afirma que:

Se eu coordenar um departamento onde começar por ter os equipamentos, etc., temos que formar os professores para a utilização deles. [...] As questões para mim são organizacionais, não é só recursos... Porque se calhar disseram-lhe que têm 200 computadores cá na escola. Têm 180, agora para que é que eles servem e quantos estão a funcionar? [Professor de Português, 58 anos]

Mesmo entre os professores que sabem utilizar a generalidade das funcionalidades adstritas à plataforma Moodle, há alguns docentes que salientam o tempo que é necessário, nomeadamente para poder produzir bons materiais para colocar na plataforma. Desta forma, alguns dos docentes optam estrategicamente por utilizações menos ambiciosas da Moodle:

Tendencialmente nos últimos anos não tenho feito tanto porque o investimento em termos de tempo que é necessário para termos aquilo bem oleado acaba por ser tanto que depois não conseguimos fazer tudo. Então tem sido, essencialmente, uma forma 
de disponibilizar em circuito mais fechado, aí sim, para os nossos alunos, os materiais que apresentamos nas aulas. [Professor de Biologia, 36 anos]

Consentaneamente, outro docente refere que:

[...] Depende também da disponibilidade de tempo que temos para desenvolver novos materiais, creio que é um dos principais obstáculos à utilização adequada. [Professor de Sociologia, 53 anos]

Outras das razões apontadas para a não utilização da Moodle são de natureza técnica. Nuns casos, são referidas dificuldades para fazer o login para poder aceder; noutros casos, são os próprios alunos que se esquecem ou perdem as passwords; noutros casos ainda, são referidas sobrecargas ao nível do servidor, o que pode bloquear o acesso à plataforma:

[...] Como havia muita gente a aceder ao site aquilo causava bloqueios. E depois começavam a haver desculpas. "Oh professora, não trouxe a ficha, porque o site estava bloqueado, não consegui entrar"; "esqueci-me da minha palavra-passe, não dava..." e os professores começaram a achar que se for através dos e-mails pessoais já não havia razão para bloquear e isso tudo. [Aluna do 12.ำ ano de Línguas e Humanidades]

Uma outra dimensão destas dificuldades técnicas é referida por um dos docentes entrevistados:

Na História da Cultura e das Artes não consigo pôr os diapositivos, o ficheiro é muito pesado. Já falei nisso ao professor de Informática e ele disse que não é fácil, porque tem muitas imagens. [Professor de História, 48 anos]

Paralelamente, uma das condições para a utilização da Moodle através dos fóruns poder funcionar com eficácia é o desenvolvimento de alguma assiduidade no acesso por parte dos docentes. Esta disponibilidade, sendo defendida por alguns é, por outros, pelo contrário, bastante rejeitada pelas mais diversas razões:

Não! Eles bem que tentam, [risos] dizem: "Eu mando o trabalho e tal...". Não, não, não! Tento fugir a isso! Porque, como sabe, como eu tenho uma relação não muito boa com o monitor, não gosto de passar muito tempo à frente. Gosto de estar à frente das pessoas, das coisas, do mundo, o mundo virtual não é o meu forte. E então fujo a isso. [Professor de Filosofia, 50 anos]

Paradoxalmente, esta mesma assiduidade constitui uma condição indispensável para alguns dos alunos inquiridos. Efetivamente, da totalidade dos alunos entrevistados apenas dois afirmaram claramente que não gostam da Moodle e, por isso, nunca a usam. Ainda assim, um deles, disse que no ano passado gostava. $O$ que o leva a não gostar este ano é a inconsistência da estratégia que o professor tem desenvolvido: 
Já utilizei na outra escola, mas na outra escola fazia sentido, aqui não [risos]. Tínhamos de fazer trabalhos, acabar em casa e enviávamos. A professora estava sempre lá, quase sempre online, falava connosco. Se eu tivesse alguma dúvida, a professora esclarecia dentro de uma hora, ou duas, era eficiente. E era extremamente benéfico para nós, e acabava também por ser bom para o professor. [...] Aqui recuámos no tempo [risos], voltei ao $4^{\circ}$. ano. [Aluna do $10 .^{\circ}$ ano de Línguas e Humanidades, 16 anos]

Para além destas dificuldades ou constrangimentos à utilização da plataforma existem, a nosso ver (e a surgir como uma presença transversal nos diversos testemunhos dos docentes entrevistados), razões mais recônditas, ao nível das configurações culturais e, dentro destas, no que respeita às representações coletivas, sobre o que deve ser entendido sobre o processo de ensino-aprendizagem. De facto, embora esta posição não seja explicitamente assumida pela generalidade dos docentes, ainda assim vislumbra-se aqui ou ali, de forma mais ou menos explícita, mais ou menos tácita, que os professores entendem que o ensino deve ser em sala de aula, na tradicional relação professor-alunos, sendo os suportes didáticos aceites pela sua completa complementaridade face a esse processo e, portanto, jamais substituindo-o. Trata-se, de uma das maiores resistências que atualmente enfrenta o ensino à distância (o chamado E-learning), mesmo nas suas abordagens mistas onde se propõe a complementação de abordagens de ensino à distância com outras de ensino presencial (B-learning). Ora, o chat ou o fórum, pela sua natureza, podem, em muitos casos, funcionar como uma ação supletiva das aulas, da mesma forma que acontece com o B-learning ou com o E-learning. A este respeito apresentamos uma reflexão de um dos docentes entrevistados:

Eu sinceramente... pronto, assim com os alunos à distância... Para tirar uma dúvida, muito bem, isso tira-se uma dúvida. Mas estar a fazer uma aula à distância, eu ainda não consigo compreender essa à distância, pronto. [Professor de Sociologia, 53 anos]

Estamos, portanto, numa situação que passa por uma quase ressocialização dos docentes para a importância de um uso coerente e continuado das TIC nas suas aulas. Trata-se de conseguir um certo nível de reconfiguração cultural que ainda está por fazer junto de muitos dos nossos professores pois são eles que, em última instância, como vimos, ditam a boa ou má dinâmica de implementação das TIC nas escolas, assim seja a sua atitude face a elas.

\section{Discussão dos resultados}

No universo de escolas por nós analisado, a Moodle apresenta uma crescente implantação, embora circunscrita, maioritariamente, à colocação de informações, fazendo pouco apelo às suas funcionalidades mais ambiciosas - os chats ou os fóruns. Ora, a possibilidade de trocar impressões e esclarecimentos entre colegas na Moodle, através dos fóruns, mesmo sem a intervenção do professor, é, por si só, um momento relevante de aprendizagem. Assim, Valente e Duarte (2007: 6, cit. em 
Pimentel 2009: 37) afirmam que: “O conhecimento persistente é construído por quem aprende, e aprendizagens partilhadas, isto é, obtidas a partir de situações em que a cooperação é valorizada, são mais eficazes." Neste sentido, Champagne e Bunce (1991) explicam que as estratégias pedagógicas que promovem interações aluno-aluno contribuem para o desenvolvimento cognitivo. Os autores referem que se trata de um processo de aprendizagem frequentemente muito útil, sendo, até, mais eficaz do que aquele que se verifica na interação professor-aluno, pois as explicações de aluno para aluno "são mais simples do que as dos adultos. [...] A distância entre o nível de compreensão de dois alunos é muito menor do que a distância entre um aluno e o professor." (1991: 31). Por esta mesma razão, Freitas (1997) salienta a importância do processo interativo entre vários alunos, em pequeno grupo, para, através deste processo, serem confrontados vários ângulos sobre a mesma questão, o que permite um maior esclarecimento dos alunos envolvidos. Situando-se igualmente neste debate, Sanches (1994) explica que a discussão de tipo académico, que tem lugar dentro de alguns grupos de alunos, permite que eles consigam desenvolver estratégias de raciocínio de maior qualidade. Sanches (1994) aduz ainda que o exercício da argumentação intelectual entre os alunos estimula o pensamento e o desenvolvimento de competências de pensamento crítico. Concordantemente, Cunha e Paiva (2003: 26, cit. em Pimentel, 2009: 49) salientam que "os Fóruns podem promover um espaço que facilite o emergir de diferentes perspetivas e dúvidas insondáveis mas também o emergir de estratégias diferentes para as colmatar." Neste debate, Pimentel (2009) convoca o socioconstrutivismo de Vigotsky, aduzindo argumentos adicionais que nos interessam. $\mathrm{O}$ autor salienta que, no ambiente colaborativo, "cria-se uma cultura de aluno, de conhecimentos e significados partilhados, permitindo a interação aluno/objeto, aluno/professor e aluno/aluno. $\mathrm{O}$ aluno passaria de uma atitude passiva de recetor de conhecimento para uma atitude ativa na construção conjunta de saberes." (2009: 43) Para o referido autor, esta ideologia socioconstrutivista aparece também defendida por Perrenoud (2002) como um meio de "democratizar o acesso aos saberes, a desenvolver a autonomia dos sujeitos, o seu sentido crítico, as suas competências de atores sociais e a sua capacidade de construir e defender um determinado ponto de vista." (Pimentel, 2009: 43). Ora, tudo isto poderá ser implementado nos chats ou nos fóruns da Moodle, desde que os alunos consigam permanecer tempo suficiente a discutir questões informativas entre si. Neste processo, Pimentel (2009), por referência a um estudo de Karayan e Crowe, destaca o facto de a qualidade das participações numa discussão online aumentar devido ao facto de os intervenientes não se sentirem pressionados pela necessidade de responder de imediato, tendo tempo para pensar e processar a sua resposta. Paralelamente, sempre que se esgotarem as soluções dos alunos para os problemas em debate, a entrada de um professor especialista nessa área poderá levar ainda mais longe estes fóruns.

Paralelamente, verificámos a total inexistência de referências efetivas à utilização dos fóruns para os professores comunicarem com as famílias dos alunos. Numa altura em que a posse de computador com ligação à Internet é praticamente ubíqua para todos os alunos, a possibilidade de estabelecer uma ponte entre a escola e a família seria uma virtualidade relevante da Moodle, fomentando processos 
de inclusão digital, aprendizagem não formal e integração comunitária (Spilker et al., 2015). De facto, são vários os autores que enfatizam a relevância de destruir as barreiras existentes entre a família dos alunos e a escola (ver, por exemplo, McDermoth e Rothenberg, 2001), desde logo pela maior operacionalidade conseguida no auxílio que as famílias procuram prestar aos seus alunos na execução dos trabalhos de casa. Ora, neste âmbito surgem frequentemente dúvidas que seriam facilmente esclarecidas se a modalidade de troca de informações entre as famílias e o professor estivesse ativa e fosse usada por ambos através dos chats ou dos fóruns (Voorhis, 2003). Na verdade, frequentemente os alunos menos favorecidos não conseguem que os seus familiares os ajudem a estudar ou a fazer os trabalhos de casa. Ora, as metodologias interativas como a Moodle permitem um contacto dos familiares com os professores que, desta forma, os podem ajudar a explicar aos seus educandos as dúvidas que vão surgindo no estudo, abrindo portas entre nós a uma prática bastante difundida nos EUA (como, por exemplo, os sobejamente conhecidos TIP (teachers involve parents in schoolwork) (Voorhis, 2003). Paralelamente, é hoje em dia reconhecido que a aprendizagem se edifica sobre a existência de mapas conceptuais (Moreira e Buchweitz, 1994; Novak e Gowin, 1996), sendo útil mobilizar os conceitos subsunçores que as crianças já possuem sobre os assuntos, providenciando uma aprendizagem significativa na aceção de Ausubel (Moreira e Buchweitz, 1994). Ao surgirem dúvidas no estudo, certas relações conceptuais podem ficar por explicar dificultando a aquisição de conhecimento posterior. O esclarecimento rápido destas dúvidas, por exemplo como é feito com os SOS Homework nos EUA, seria uma forma de facilitar este processo obstando a essas limitações conceptuais.

Além disso, cabe referir que ainda não existe entre nós uma política comum consistente, muito menos uniforme, de utilização da Moodle (e do conjunto das suas funcionalidades) emanada do Ministério da Educação e Ciência para todas as escolas. Podendo este aspeto ser parcialmente positivo porque as necessidades de formação e de preparação dos alunos variam de escola para escola, segundo as especificidades dos respetivos territórios educativos, no entanto, mesmo dentro de cada escola, percebe-se que, na maioria dos casos por nós observados, não existe uma política concertada face à Moodle (formação, utilização e desenvolvimento) por parte das respetivas direções, ficando o seu uso a depender de uma certa aleatoriedade decorrente da maior ou menor apetência e do perfil dos professores para a sua implementação em sala de aula. Esta permanente ambivalência associada à utilização da Moodle (numas unidades curriculares usa-se muito, noutras nada; em algumas ciências é apresentada como muito útil, noutras como um entrave à ciência...) suscita, desde logo, elevados níveis de aleatoriedade nas estratégias de estudo dos próprios alunos face ao uso dessa mesma plataforma, aparecendo fortemente vinculados a ela nuns casos, menos noutros e nada noutros ainda. Se, como vimos, a grande maioria dos alunos inquiridos afirmou que usa, com maior ou menor regularidade, os diversos chats e fóruns que existem nas redes sociais, então o facto de não se verificar, por parte desses mesmos alunos, a transferibilidade dessas práticas e desse saber desses chats e desses fóruns para os correspondentes da Moodle (cuja natureza, princípios e funcionamento são exatamente iguais) deve-se à impreparação de alguns professores, crescentemente inadaptados às linguagens 
e às tecnologias que hoje em dia predominam entre os nossos alunos, subaproveitando tecnologias educativas que poderiam potencializar o processo de ensino-aprendizagem, denunciando tendências de inadequação pedagógica que já tínhamos identificado noutros estudos (Dias, 2011). O alerta de Carvalho (2007: 26) faz aqui todo o sentido:

É imperioso preparar as gerações para esta nova forma de estar, onde todos são consumidores e produtores e onde as capacidades de pesquisar e de avaliar a qualidade da informação são críticas.

\section{Conclusão}

A utilização da plataforma Moodle, enquanto um dos eixos relevantes do desenvolvimento das TIC no âmbito do nosso sistema de ensino, tem conhecido um progresso assinalável. Contudo, apesar de a sua utilização conter em si uma pluralidade de funcionalidades conexas, a verdade é que, entre nós, na grande maioria dos casos analisados, continuam a predominar as funcionalidades exclusivamente complementares das aulas tradicionais, através da colocação de informação na Moodle e pouco mais. Também Pimentel (2009) refere níveis consentâneos de implantação da plataforma, no estudo que desenvolveu no agrupamento de escolas Júlio Brandão. A razão impeditiva mais marcante para este subaproveitamento da Moodle por parte dos professores que inquirimos prende-se com a sua deficiente formação. Neste âmbito, pudemos constatar certas contradições entre as direções de algumas escolas e os docentes: aquelas centralizam-se, maioritariamente, na aquisição de equipamentos em detrimento da formação para as TIC e, concretamente, para a Moodle; enquanto alguns docentes, pelo contrário, referem que já existem equipamentos suficientes, o que lhes falta são ações de formação para poderem fazer efetivo uso deles. Mormente, são ainda referidas como razões impeditivas de um uso mais ambicioso da Moodle algumas dificuldades técnicas, faltas de tempo e, ainda, resistências por parte dos alunos, o que, atendendo ao uso que eles fazem das TIC noutros contextos, se percebe ser, por sua vez, resultante da já referida inadequada utilização que lhes é dada pelos professores.

Neste artigo, tendo enquadrado e identificado o uso da Moodle entre nós e as limitações a um uso mais ambicioso, não perspetivámos, concretamente, em que termos o uso desta plataforma informática se articula com as estratégias de estudo dos alunos, questão à qual procuraremos dar resposta em futuros trabalhos.

\section{Referências bibliográficas}

Alves, M. (2008), O Computador e a Internet como Instrumentos Pedagógicos. Estudo Exploratório com Professores do 2.ำ e do 3.ำ ciclo do Ensino Básico e do Ensino Secundário de Escolas do Concelho de Vila Verde, Braga, Universidade do Minho, tese de mestrado em Educação. 
Badge, J. L., A. J. Cann, e J. Scott (2005), “E-learning versus e-teaching: seeing the pedagogic wood for the technological trees", Bioscience Education, 5, disponível em: http://users.humboldt.edu/joan/moodle/all.htm (consultado a 27/02/2008).

Bottentuit Junior, J., e C. Coutinho (2007), “Projecto e desenvolvimento de um laboratório virtual na plataforma moodle", V Conferência Internacional de Tecnologias de Informação e Comunicação, Challenges 2007, 17 e 18 de maio, Braga, Universidade do Minho.

Brito, C., J. Duarte, e M. Baía (2004), As Tecnologias de Informação na Formação Contínua de Professores. Uma Nova Leitura da Realidade, Lisboa, Editorial do Ministério da Educação.

Brophy, Jere (2000), Teaching, Educational Practices Series, 1, Genebra, International Bureau of Education.

Bryan, Tanis, e Karen Burstein (2004), “Improving homework completion and academic performance: lessons from special education", Theory into Practice, 43 (3), pp. 198-205.

Carvalho, A. A. (2007), “Rentabilizar a internet no ensino básico e secundário: dos recursos e ferramentas online aos LMS", Revista Sísifo, 3, pp. 25-40.

Carvalho, A., N. Areal, e J. Silva (2011), “Students' perceptions of Blackboard and Moodle in a Portuguese university", British Journal of Educational Technology, 42 (5), pp. 824-841.

Champagne, Audrey, e Diane Bunce (1991), "Learning-theory-based science teaching", em S. E. Glynn, R. H. Yeany e B. K. Britton (orgs.), The Psychology of Learning Science, Hillsdale, NJ, Lawrence Earlbaum Associates.

Cooper, H., K. Jackson, B. Nye, e J. J. Lindsay (2001), “A model of homework's influence on the performance evaluations of elementary school students", Journal of Experimental Education, 69 (2), pp. 181-199.

Cosden, Merith, Gale Morrison, Lisa Gutiérrez, e Megan Brown (2004), “The effects of homework programs and after-school activities on school success", Theory into Practice, 43 (3), pp. 174-181.

Costa, F. A. (coord.) (2008), Competências TIC. Estudo de Implementação, vol. 1, Lisboa, Gabinete de Estatística e Planeamento da Educação (GEPE), Ministério da Educação.

Coutinho, C. P., e M. Alves (2010), “Educação e sociedade da aprendizagem: um olhar sobre o potencial educativo da Internet", Revista de Formación e Innovatición Educativa Universitaria, 3 (4), pp. 206-225.

Cunha, F., e J. Paiva (2003), A Utilização de Fóruns em Contexto de Ensino e Aprendizagem, disponível em: http://www.nonio.uniminho.pt/challenges/05comunicacoes/Tema1/03FernandoCu nha.pdf (consultado a 19/03/2008).

Dias, Paulo (2011), "Estratégias de estudo dos alunos no âmbito dos processos de socialização", Sociologia, Problemas e Práticas, 66, pp. 71-94.

Ferrés, J. (2004), Vídeo y Educación, Barcelona , Paidós.

Freitas, Cândido (1997), "A integração das NTI no processo de ensino-aprendizagem”, em AA.VV., Tecnologias de Informação e Comunicação na Aprendizagem, Lisboa, Instituto de Inovação Educacional, pp. 11-20.

Garrido, J. (2008), “Evolução para E-Learning 2.0: implicações para o design de aprendizagens num ensino à distância com recurso à Internet", comunicação 
apresentada no III Congresso de Educação à Distância dos Países de Lingua Portuguesa, 2008, disponível em: http://www.n-learning.blogspot.com/ (consultado a 24/05/2008).

GEPE - Gabinete de Estatística e Planeamento da Educação (2010), Estatísticas da Educação 2008/2009, Lisboa, GEPE, disponível em: http://apcrsi.pt/dossiers/estatistica_gepe/GEPE_estatisticas_da_educa_2008_2009.p df (última consulta em abril de 2016).

Hagenaars, J. (1994), Loglinear Models with Latent Variables, Londres, Sage Publications.

Hall, C. (2006), Lighting a Fire or Filling a Pail? Users' Perceptions of a Virtual Learning Environment, Survey Report, University of Swansea, disponível em: http://learninglab.swan.ac.uk/Downloads/User_Survey_Report\%201.1.pdf (consultado a 28/02/2008).

Hinson, J. M. (2005), “Investigating the perceptions and behaviours of elementary students and teachers when Internet access is universal", Computers in the Schools, 22 (1-2), pp. 19-31, disponível em: http://www.scopus.com (consultado a 13/10/2006).

Hirsch, E. D. (1998), "Reality's revenge: research and ideology", Arts Education Policy Review, 99 (4), pp. 3-15.

Hoover-Dempsey, K. V., A. C. Battiato, J. M. T. Walker, R. P. Reed, J. M. Delong, e K. P. Jones (2001), "Parental involvement in homework", Educational Psychologist, 36, pp. 195-209.

Knoke, D., e P. Burke (1991), Log-Linear Models, Londres, Sage Publications.

Lee, F. L., e R. M. Heyworth (2000), “Electronic homework”, Journal of Educational Computing Research, 22 (2), pp. 171-186.

Lisbôa, E., A. Jesus, A. Varela, G. Teixeira, e C. Coutinho (2009), “LMS em contexto escolar: estudo sobre o uso da Moodle pelos docentes de duas escolas do Norte de Portugal", Educação, Formação e Tecnologias, 2 (1), pp. 44-57.

McDermott, Peter, e Julia Rothenberg (2001), “The characteristics of effective teachers in high poverty schools: triangulating our data", comunicação apresentada no Annual Meeting of the American Educational Research Association, Nova Orleães, LA, 24-28 de abril.

Monereo, C. (2005), “Internet, un espacio idóneo para desarrollar las competencias básicas", em C. Monero (coord), Internet y Competências Básicas. Aprender a Colaborar, a Comunicarse, a Participar, a Aprender, Barcelona, Editorial Graó, pp. 6-26.

Moreira, Marco, e Bernardo Buchweitz (1994), Novas Estratégias de Ensino e Aprendizagem. Os Mapas Conceptuais e o Vê Epistemológico, Lisboa, Plátano Edições Técnicas.

Novak, J., e D. Gowin (1996), Aprender a Aprender, Lisboa, Plátano Edições Técnicas.

OECD (2004), Education at a Glance: OEDC Indicators - 2004 Edition. Paris, OECD.

Paiva, J. (2002), As Tecnologias de Informação e Comunicação. Utilização pelos Professores, Lisboa, ME/DAPP.

Perrenoud, P. (2002), A Prática Reflexiva no Ofício de Professor. Profissionalização e Razão Pedagógica, Porto Alegre, Artmed Editora.

Piano, A. R. (2007), Vinte Anos de Investigação sobre Tecnologias Educativas em Portugal. Uma Sistematização da Investigação Desenvolvida entre 1985 e 2005, Lisboa, Faculdade de Psicologia da Universidade de Lisboa, tese de mestrado.

Pimentel, Paulo (2009), Impacto da Plataforma Moodle nas Escolas de Famalicão. Um Estudo de Caso, Braga, Universidade do Minho, tese de mestrado. 
Reach, Kelle, e Harris Cooper (2004), “Homework hotlines: recommendations for successful practice", Theory into Practice, 43, pp. 220-227.

Sanches, Maria (1994), “Aprendizagem cooperativa: resolução de problemas em contexto de auto-regulação", Revista de Educação, IV (12), pp. 31-42.

Santos, J. R. (2012), “A Moodle nas práticas pedagógicas de uma escola básica: realidade ou ficção na inserção das TIC na sala de aula", Educação, Formação e Tecnologias, 5 (1), pp. 72-83.

Santos, J. R., e M. I. Gaspar (2014), “TIC nas escolas portuguesas: contributos das lideranças, revista EDaPECI, 14 (1), pp. 36-54.

Shulman, Lee (1989), "Paradigmas y programas de investigación en el estudio de la enseñanza: una perspectiva contemporánea", em Merlin Wittrock (org.), La Investigación de la Enseñanza. Enfoques, Teorías y Métodos, Barcelona, Editorial Paidós, pp. 9-91.

Shumow, L., e J. D. Miller (2001), “Parent's at-home and at-school academic involvement with young adolescents", Journal of Early Adolescence, 21 (1), pp. 68-91.

Silva, R. (2005), “Gestão da aprendizagem e do conhecimento", em R. Silva e A. Silva (orgs.), Educação, Aprendizagem e Tecnologia. Um Paradigma para Professores do Século XXI, Lisboa, Edições Sílabo, pp. 121-138.

Spilker, Maria João, e outros (2014), “O Moodle como ambiente facilitador da inclusão e literacia digital: a experiência da uma comunidade de aprendizagem", Atas do Colóquio Luso-Brasileiro de Educação à Distância e Elearning, Lisboa, LEAD/Universidade Aberta.

Simão, J. (2006), "Relação entre os blogs e webjornalismo", Revista Prisma, 3, pp. 148-164.

Valente, L., e P. Duarte, (2007), “Moodle: moda, mania ou inovação na formação? Testemunhos do Centro de Competência da Universidade do Minho", em P. Dias, C. Freitas, B. Silva, A. Osório e A. Ramos, V Conferência Internacional de Tecnologias da Informação e da Comunicação na Educação - Challenges 2007, Braga, Centro de Competência da Universidade do Minho, pp. 781-790.

Voorhis, Van F. (2003), “Interactive homework in middle school: effects on family involvement and science achievement", Journal of Educational Research, 96 (6), pp. 323-338.

Paulo Coelho Dias (corresponding author). Professor adjunto na Escola Superior de Educação do Instituto Politécnico de Santarém. Complexo Andaluz, Apartado 131, 2001-902 Santarém. Tel. 243309180 (extensão 04170); fax. 243309189. Investigador, Instituto Universitário de Lisboa (ISCTE-IUL), Centro de Investigação e Estudos de Sociologia (CIES), Av. das Forças Armadas - ISCTE; 1649-026 Lisboa, Portugal. Tel: +351 217903077 ou +351 217941 404; fax: +351 217 940 074.E-mail: paulo.dias@ese.ipsantarem.pt ou:pgdias@sapo.pt

Nuno de Almeida Alves. Professor auxiliar no Instituto Universitário de Lisboa (ISCTE-IUL), Centro de Investigação e Estudos de Sociologia (CIES), Av. das Forças Armadas - ISCTE; 1649-026 Lisboa, Portugal. Tel: +351 217903077 ou +351 217941 404; fax: +351 217940 074. E-mail: nalmeidaalves@iscte.pt 
Pedro Abrantes. Investigador no Instituto Universitário de Lisboa (ISCTE-IUL), Centro de Investigação e Estudos de Sociologia (CIES), Av. das Forças Armadas ISCTE; 1649-026 Lisboa, Portugal. Tel: +351 217903077 ou +351 217941 404; fax: +351217940 074. E-mail: pedro.abrantes@iscte.pt

Carla F. Rodrigues. Investigadora no Instituto Universitário de Lisboa (ISCTE-IUL), Centro de Investigação e Estudos de Sociologia (CIES), Av. das Forças Armadas - ISCTE; 1649-026 Lisboa, Portugal. Tel: +351 217903077 ou +351 217941 404; fax: +351 217940 074. E-mail: carla.af.rodrigues@gmail.com

Receção: 25 de outubro de 2014 Aprovação: 10 de março de 2016 